\title{
Analysis of the instability phenomena caused by steam in high-pressure turbines
}

\author{
Paolo Pennacchi* and Andrea Vania \\ Politecnico di Milano, Department of Mechanical Engineering, Via La Masa 1, 20156 Milan, Italy
}

Received 1 August 2009

Revised 12 March 2010

\begin{abstract}
Instability phenomena in steam turbines may happen as a consequence of certain characteristics of the steam flow as well as of the mechanical and geometrical properties of the seals. This phenomenon can be modeled and the raise of the steam flow and pressure causes the increase of the cross coupled coefficients used to model the seal stiffness. As a consequence, the eigenvalues and eigenmodes of the mathematical model of the machine change. The real part of the eigenvalue associated with the first flexural normal mode of the turbine shaft may become positive causing the conditions for unstable vibrations. The original contribution of the paper is the application of a model-based analysis of the dynamic behavior of a large power unit, affected by steam-whirl instability phenomena. The model proposed by the authors allows studying successfully the experimental case. The threshold level of the steam flow that causes instability conditions is analyzed and used to define the stability margin of the power unit.
\end{abstract}

Keywords: Rotordynamics, steam-whirl, steam-whip, instability, model based analysis

\section{Introduction}

Steam-whirl instability phenomena in rotating machines can cause a very quick growth of the amplitude of the shaft vibrations that can reach high levels in a very short time. In general, the occurrence of subsynchronous vibrations is a typical symptom of this malfunction. Contrary to oil-whirl subsynchronous vibrations due to fluid-film destabilizing forces in journal bearings [1-3], the frequency of the subsynchronous vibrations caused by steam-whirl phenomena can be rather different from half of the shaft rotating frequency. Sometimes the frequency of these subsynchronous vibrations is rather close to the damped natural frequency associated with the first flexural normal mode of the turbine shaft evaluated at the operating speed [4]. With regard to this, it is important to consider that steam-whirl instability onsets generally occur in on-load operating conditions characterized by high values of steam pressure and flow [5-7]. Moreover, the machine running speed can be significantly higher than the first flexural critical speed of the steam turbine shafts that are included in the machine-train. Therefore, the synchronization between the frequency of the subsynchronous destabilizing forces generated by the seals and the frequency associated with a flexural critical speed, commonly the first one, is not unusual. In this case, the large energy flow introduced into the rotor system by the destabilizing forces can cause very high levels of subsynchronous vibrations of the shaft. Depending on the sign of the modal damping factor associated with the first flexural critical speed, vibrations with expanding amplitude may happen. In this case, even if this term is not used in literature, the phenomenon should be more precisely defined as steam-whip instability.

In general, the dynamic stiffness of the seals are modeled by means of linearized coefficients that are significantly influenced by the seal geometrical characteristics [5]. Further parameters that provide important contributions to

\footnotetext{
*Corresponding author. Tel.: +39 022399 8440: Fax: +39 022399 8492; E-mail: paolo.pennacchi@polimi.it.
} 
the value of the seal stiffness coefficients in steam turbines are the steam pressure and flow. The main destabilizing effects are the unsymmetrical circumferential pressure distribution and the unbalanced torque forces due to the varying radial clearance of the seals $[8,9]$. Therefore, the actual available radial clearance, which depend on the eccentricity ratio of the shaft, plays a basic role in the magnitude and frequency of the destabilizing forces generated by the seals [10-13].

In general, the main dynamic effects of the seals in steam turbines can be modeled by means of cross-coupled coefficients that have the same magnitude and opposite sign $[5,13,14]$. The raise of the steam pressure and flow, which is basically related to the raise of the megawatt load, often causes a considerable increasing of the crosscoupled stiffness coefficients of the seals [15-17]. Therefore, at high power levels, the considerable increase of the seal stiffness coefficients can cause important changes in some modal damping factors associated with the flexural critical speeds of the machine-train as well as in the shape of the respective normal modes of the shafts. Depending on the sign of the modal damping factors, the condition for the generation of unstable vibrations can occur.

This phenomenon can be investigated by means of the analysis of the eigenvalues of the rotating machine model performed at the operating speed $[18,19]$. Different case studies must be carried out considering the seal stiffness coefficients associated with different values of the steam flow. The results of this analysis allow the changes of the flexural critical speeds and the respective modal damping factors, due to the seal stiffening, to be investigated. Sometimes the progressive growth of the seal stiffness coefficients causes the values of two or more flexural critical speeds of the shaft-train to converge.

The paper proposes the analysis of the progressive changes of the real and imaginary parts of the system eigenvalues as well as the analysis of the changes in the shape of the eigenmodes of the shaft-train. This provides very interesting information that can be used to optimize the machine design and to adjust some process parameters of the plant that can allow the rotating machine to be temporarily operated in safety condition by reducing the seal stiffness magnitude or by causing suitable changes of the dynamic stiffness of the oil-film journal bearings. The same analysis proposed here allows the threshold level of steam flow, or load, that causes steam-whirl instability phenomena to be evaluated. On the basis of these results, the stability margin of the power unit can be easily determined as the amount of extra steam flow, in comparison to the nominal rating, needed to cause unstable vibrations.

A more accurate evaluation of the stability margin can be obtained by applying perturbation techniques in actual operating conditions of the rotating machine [20,21]. Since this strategy is based on experimental tests, it takes into account the actual non-linear effects in the machine response whose importance may become considerable when high vibration levels due to instability phenomena occur.

This paper shows also the results of the model-based analysis of the dynamic behavior of a large power unit affected by steam-whirl instability phenomena. The changes of the real and imaginary parts of the system eigenvalues, along with the changes in the shape of the respective eigenmodes of the shaft-train caused by the increase of the seal stiffness, have been studied by means of a parametric analysis. This allowed the dependence of the seal stiffness on the steam flow and the effects of shaft-to-seal misalignments on the machine vibrations to be investigated. The stability margin of the power unit has been evaluated for both aligned and misaligned seals of the high pressure (HP) steam turbine. The results of these studies have been compared with experimental findings.

Moreover, the effects of suitable changes of the flexural stiffness of the HP turbine shaft on the stability margin of the unit have been investigated, in order to prevent the occurrence of steam-whirl instability phenomena even in the case of partial misalignments of the seals as well as in the case of an underestimation of the actual values of the cross-coupled stiffness coefficients.

\section{Definition of the instability factor and of the analysis criteria}

The fully assembled rotating machine considered here is composed of a shaft-train, journal bearings and a foundation structure. The dynamic behavior of the system can be studied using model-based techniques [22]. A finite element model (FEM) is often used to describe the mechanical properties of the shaft-train, while the dynamic effects caused by seals, fluid-film journal bearings and rolling bearings can be modeled by means of dynamic stiffness coefficients that may depend on the shaft rotating speed. In the end, machine casings, supports and foundation 
structure can be modeled by means of well known different techniques [22-25] here not described in detail for the sake of brevity.

The free motion equation of a rotating machine can be expressed as:

$$
[M] \ddot{\mathbf{x}}+([C]+[G]) \dot{\mathbf{x}}+[K] \mathbf{x}=0
$$

where $\mathbf{x}$ is the vector that contains the translational and angular displacements associated with the degrees of freedoms (d.o.f.s) of shafts and foundation.

The mass, stiffness and damping matrices $[M],[K]$ and $[C]$ describe the dynamic effects of the whole rotating machine while the matrix $[G]$ takes into account the gyroscopic effects of the shaft-train.

The dynamic effects caused in steam turbines by the stiffness of the seals can be modeled by means of a pair of cross-coupled coefficients, having the same magnitude and opposite sign, that are assembled in the off-diagonal locations of the stiffness matrix $\left[K_{s}\right]_{j}$ associated with the $j$-th seal. In a fixed frame coordinate system $x y$ this matrix can be written as:

$$
\left[K_{s}\right]_{j}=\left[\begin{array}{cc}
0 & k_{x y} \\
k_{y x} & 0
\end{array}\right]
$$

where $k_{x y}=-k_{y x}[5,13,14]$. These stiffness coefficients, which are assembled in suitable locations of the global stiffness matrix $[K]$, depend on various factors like the seal geometry, the steam pressure and flow [19]. Moreover, pre-swirling and injection can significantly affect the seal stiffness coefficients.

In power units, whose machine-train contains steam turbines, the raise of megawatt load and steam flow can causes a significant hardening of the cross-coupled stiffness coefficients of the seals defined by Eq. (2). They can be responsible for self-excited rotor instability phenomena characterized by a subsynchronous shaft whirl that is generally associated with the first flexural normal mode of the rotor. The analysis of the eigenvalues of the rotating machine model can be used to point out the conditions that must be satisfied for the occurrence of unstable vibrations. The $k$-th complex eigenvalue of the model can be written as:

$$
\lambda_{k}=-\sigma_{k}+i 2 \pi f_{d k}
$$

where $f_{d k}$ is the $k$-th damped natural frequency of the system while $\sigma_{k}$ is the respective modal damping factor. In order to cause energy dissipation the factor $\sigma_{k}$ must be positive. The respective undamped natural frequency is given by:

$$
f_{n k}=\frac{1}{2 \pi} \sqrt{\left(2 \pi f_{d k}\right)^{2}+\sigma_{k}^{2}}
$$

The $k$-th dimensionless damping factor, $h_{k}$, can be expressed in the following form:

$$
h_{k}=\sigma_{k} /\left(2 \pi f_{d k}\right)
$$

In order to have oscillating motions the dimensionless damping factor must be positive and lower than unity. Under the assumption that the rotor system vibrates in the free motion with an harmonic law having a frequency equal to the $k$-th damped natural frequency $f_{d k}$, the time history of the displacements evaluated at the $j$-th d.o.f. $x_{j}$ can be written as:

$$
x_{j}(t)=X_{j} e^{-\sigma_{k} t} \cos \left(2 \pi f_{d k} t+\varphi_{j}\right)
$$

Let us denote $T_{k}$ the time period associated with the frequency $f_{d k}$. The corresponding instability factor $V_{k}$ can be expressed by the ratio between the vibration amplitudes evaluated at the two instants $t_{1}$ and $t_{2}$ that satisfy the following relationship: $t_{2}=t_{1}+T_{k}$. Then, the logarithm of the instability factor is given by:

$$
\ln \left(V_{k}\right)=-2 \pi h_{k} / \sqrt{1-h_{k}^{2}}
$$

When the instability factor $V_{k}$ exceeds unity, the rotating machine can be affected by instability phenomena. In general, the destabilizing forces due to the oil-film forces in journal bearings cause subsynchronous vibrations of the shaft whose frequency is very close to half the rotating frequency $(0.5 \mathrm{X})$ [1-3]. In contrast, the whirling phenomena due to the effects of seals mainly cause subsynchronous vibrations whose harmonic order depends on the geometrical 
properties of the seals as well as on some basic characteristics of the fluid flow. The fluid average circumferential velocity ratio plays a basic role in determining the order of the subsynchronous vibrations [10]. When the frequency of these vibrations is close to the first flexural critical speed of the turbine shaft, the risk of the occurrence of serious steam-whip instability phenomena becomes more critical. Owing to the characteristics of the instability phenomena, the amplitude of the subsynchronous vibrations can grow very quickly causing severe and catastrophic damages if an automatic machine trip is not timely activated by a suitable protection system. When the machine operating conditions cause the instability factor to approach its respective threshold level, the non-linear effects in the dynamic behavior of the system may become considerable. Therefore, a non-linear model of the machine-train should be used to perform a more accurate analysis of steam-whip instability phenomena [26].

Let us denote $k_{x y i}^{*}$ the stiffness coefficient of the $i$-th seal evaluated considering the rated load. Accurate estimates of the seal stiffness coefficients associated with specific operating conditions can be obtained by means of suitable simulation models or CFD calculations [17], however, within a preliminary study of the dynamic behavior of a steam-turbine power unit, approximated estimates of these parameters can be obtained by multiplying the nominal value of the seal stiffness coefficients $k_{x y i}^{*}$ by the dimensionless megawatt load $L_{j}^{*}$ defined as the ratio between the load $L_{j}$ and the rated load $L_{r}$ of the unit. That is, within a preliminary approximated study, the seal stiffness coefficients can be considered proportional to the megawatt load. Therefore, the seal stiffness coefficients $k_{x y i}\left(L_{j}\right)$ associated with the load $L_{j}$ are given by:

$$
k_{x y i}\left(L_{j}\right)=\frac{L_{j}}{L_{r}} k_{x y i}^{*}
$$

Although this method is not based on a rigorous scientific approach, it is commonly used by steam turbine manufacturers, within investigations on the machine stability margin, to obtain a rough estimate of the seal stiffness coefficients corresponding to different values of the load. In this regard it is important to consider that the study of the machine stability requires to perform a parametric analysis in order to investigate the sensitivity of the steam turbine stability margin to the seal stiffness hardening caused by the load rises. Within this study, satisfactory results can be obtained also considering rough estimates of the seal coefficients not necessarily evaluated by means of a very accurate analysis. In fact, it is important to emphasize that a rigorous evaluation of the seal stiffness coefficients would require to take into account also many parameters whose actual values are affected by a fairly high degree of uncertainty, like hot machine alignment, seal clearances, local steam temperature and machine thermal expansions.

Moreover, also the changes of the instantaneous position of the shaft inside the seal, caused by the machine vibrations, can generate significant fluctuations of the actual values of the seal coefficients in the neighborhood of the respective average value. In the case of not negligible levels of the machine vibrations, like those that can occur in the mid-span of the HP-IP turbine, a non-linear model should be used to study the machine stability.

In the end, in the power units like that considered in this investigation, the number of seals mounted on the HP-IP steam turbine is so large that only a 3D Finite Element Model of the shaft having huge number of degrees of freedom would represent in detail the dynamic effects caused by the seals. Therefore, in common rotating machine models, like that used in the present study, only equivalent stiffness coefficients that simulate the effects of suitable groups of seals are considered. Nevertheless the practice shows that within a parametric analysis satisfactory results can be obtained also by means of these simplified models. Undoubtedly the evaluation of the mechanical characteristics of a single seal would require to apply a more rigorous approach.

In this regard it is important to emphasize that the object of this paper is not to investigate the capabilities of accurate techniques for the evaluation of seal stiffness coefficients, but to check the reliability of the results obtained by applying a standard procedure for the analysis of the stability margin of shaft-trains to the risk of the occurrence of steam-whip phenomena. Within this kind of study, based on a parametric analysis, the accuracy with which the seal stiffness coefficients included in the machine model have been defined is adequate in relation to the needs of the investigation. The satisfactory accordance between experimental evidences and numerical results obtained in this case study confirms this assumption.

The threshold level of the load, and then of the flow, that causes the instability factor $V_{k}$ to reach and exceed the unit value can be used to define the stability margin of the power unit. Since megawatt load and steam flow are highly correlated each other, and both significantly affect the seal stiffness coefficients, the load is often used in spite of the steam flow to define the stability margin. 


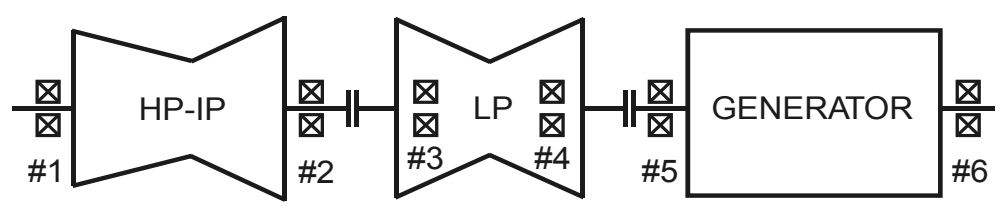

Fig. 1. Machine-train diagram and support numbers.

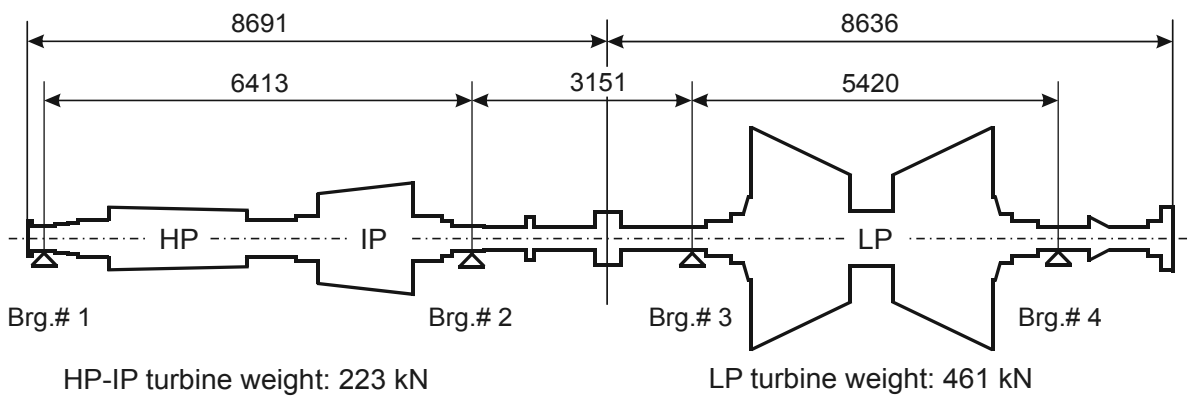

Fig. 2. Main geometrical characteristics of the HP-IP and LP turbines.

In general the instability threshold of a steam turbine is associated with a critical megawatt load, $L_{c}$, that is significantly higher than the rated load, $L_{r}$. Therefore, the stability margin, $S M$, can be defined as:

$$
S M=\left(L_{c}-L_{r}\right) / L_{r}
$$

Abnormal values of the seal stiffness coefficients, e.g. caused by a misalignment between seals and turbine shaft, can be simulated by means of the Eq. (8) in which fictitious dimensionless loads higher than unity are considered. In order to study the effects of an undesired seal stiffening on the stability margin of the rotor system, the changes of the eigenvalues of the machine model evaluated at the operating speed considering load values higher than the rated load can be investigated. This strategy allows the threshold level of load that causes the instability factor to exceed the unit value to be identified. Turbine generator sets are operated in safety conditions when this threshold level is sufficiently high.

\section{Analysis of a case history}

The subsynchronous vibrations occurred in a $240 \mathrm{MW}$ power unit, caused by steam-whip phenomena, have been analyzed. The machine-train was composed of a single-flow high pressure turbine (HP), a single-flow intermediate pressure turbine (IP), a double-flow low pressure turbine (LP) and a generator. The shafts of the machine-train were interconnected by means of common rigid couplings. The operating speed of this unit was $3000 \mathrm{rpm}$. This steam turbine unit was installed with two gas-turbine units of $320 \mathrm{MW}$ in the same combined-cycle power plant.

The shaft-train of the steam-turbine unit was mounted on six oil-film journal bearings. Figure 1 shows the machine-train diagram and the support numbers while in Fig. 2 the main geometrical characteristics of the HP-IP and LP turbines are illustrated.

The LP turbine and the generator were mounted on elliptical journal bearings while the shaft of the HP-IP turbine was mounted on two tilting-pad journal bearings having six shoes. This type of bearing was chosen just to prevent the risk of unstable vibrations.

The main geometrical characteristics of the journal bearings from \#1 to \#4, mounted on the two steam turbines, are reported in Tables 1 and 2. The stiffness and damping coefficients of the above mentioned oil-film journal bearings, evaluated at the operating speed of $3000 \mathrm{rpm}$, are shown in Tables 3 and 4.

Each support was equipped with a vertical seismic transducer and a pair of XY proximity probes whose orientation is shown in Fig. 3. 
Table 1

Geometrical characteristics of tilting-pad journal bearings \#1 and \#2

\begin{tabular}{lcccccccc}
\hline Bearing & $\begin{array}{c}\text { Diameter } \\
{[\mathrm{mm}]}\end{array}$ & $\begin{array}{c}\text { Length of } \\
\text { pad } \\
{[\mathrm{mm}]}\end{array}$ & $\begin{array}{c}\text { Pad bore } \\
\text { clearance ratio } \\
C_{p} / D\end{array}$ & $\begin{array}{c}\text { Preload } \\
\text { factor }\end{array}$ & $\begin{array}{c}\text { Pad angular } \\
\text { amplitude } \\
\text { [degree] }\end{array}$ & $\begin{array}{c}\text { Pad pivot } \\
\text { offset ratio }\end{array}$ & $\begin{array}{c}\text { Oil viscosity } \\
\text { grade } \\
\text { ISO VG }\end{array}$ & $\begin{array}{c}\text { Bearing } \\
\text { load } \\
{[\mathrm{kN}]}\end{array}$ \\
\hline$\# 1$ & 356 & 178 & 0.0014 & 0.25 & $55^{\circ}$ & 0.6 & 32 & 90.9 \\
$\# 2$ & 381 & 255 & 0.0014 & 0.25 & $55^{\circ}$ & 0.6 & 32 & 132.1 \\
\hline
\end{tabular}

Table 2

Geometrical characteristics of elliptical journal bearings \#3 and \#4

\begin{tabular}{lccccccc}
\hline Bearing & $\begin{array}{c}\text { Diameter } \\
{[\mathrm{mm}]}\end{array}$ & $\begin{array}{c}\text { Length of } \\
\text { pad } \\
{[\mathrm{mm}]}\end{array}$ & $\begin{array}{c}\text { Bore clearance } \\
\text { ratio } \\
C_{p} / D\end{array}$ & $\begin{array}{c}\text { Preload } \\
\text { factor }\end{array}$ & $\begin{array}{c}\text { Lobe angular } \\
\text { amplitude } \\
\text { [degree] }\end{array}$ & $\begin{array}{c}\text { Oil viscosity } \\
\text { grade } \\
\text { ISO VG }\end{array}$ & $\begin{array}{c}\text { Bearing } \\
\text { load } \\
{[\mathrm{kN}]}\end{array}$ \\
\hline$\# 3$ & 406 & 284 & 0.0026 & 0.5 & $170^{\circ}$ & 32 & 230.5 \\
$\# 4$ & 483 & 290 & 0.0026 & 0.5 & $170^{\circ}$ & 32 & 230.5 \\
\hline
\end{tabular}

Table 3

Oil-film stiffness coefficients of bearings from \#1 to \#4, evaluated at $3000 \mathrm{rpm}$

\begin{tabular}{lcccc}
\hline & \multicolumn{4}{c}{ Stiffness coefficients } \\
\cline { 2 - 5 } & $k_{v v}$ & \multicolumn{1}{c}{$k_{v h}$} & $k_{h v}$ & $k_{h h}$ \\
\hline Bearing N. & {$[\mathrm{N} / \mathrm{m}]$} & {$[\mathrm{N} / \mathrm{m}]$} & {$[\mathrm{N} / \mathrm{m}]$} & {$[\mathrm{N} / \mathrm{m}]$} \\
$\# 1$ & $1.1977 \times 10^{9}$ & 0.0000 & 0.0000 & $8.4849 \times 10^{8}$ \\
$\# 2$ & $1.3169 \times 10^{9}$ & 0.0000 & 0.0000 & $1.0341 \times 10^{9}$ \\
$\# 3$ & $4.6190 \times 10^{9}$ & $-2.3568 \times 10^{9}$ & $-3.6420 \times 10^{8}$ & $8.9108 \times 10^{8}$ \\
$\# 4$ & $2.8669 \times 10^{9}$ & $-1.6273 \times 10^{9}$ & $-1.6469 \times 10^{8}$ & $6.1053 \times 10^{8}$ \\
\hline
\end{tabular}

Table 4

Oil-film damping coefficients of bearings from \#1 to \#4, evaluated at $3000 \mathrm{rpm}$

\begin{tabular}{lcccc}
\hline & \multicolumn{4}{c}{ Damping coefficients } \\
\cline { 2 - 5 } & $c_{v v}$ & $c_{v h}$ & $c_{h v}$ & $c_{h h}$ \\
\hline Bearing N. & {$[\mathrm{N} \cdot \mathrm{s} / \mathrm{m}]$} & {$[\mathrm{N} \cdot \mathrm{s} / \mathrm{m}]$} & {$[\mathrm{N} \cdot \mathrm{s} / \mathrm{m}]$} & {$[\mathrm{N} \cdot \mathrm{s} / \mathrm{m}]$} \\
$\# 1$ & $3.8965 \times 10^{6}$ & 0.0000 & 0.0000 & $3.0887 \times 10^{6}$ \\
$\# 2$ & $5.5897 \times 10^{6}$ & 0.0000 & 0.0000 & $5.0592 \times 10^{6}$ \\
$\# 3$ & $1.3020 \times 10^{7}$ & $-3.0562 \times 10^{6}$ & $-3.0562 \times 10^{6}$ & $1.7227 \times 10^{6}$ \\
$\# 4$ & $9.2477 \times 10^{6}$ & $-2.1640 \times 10^{6}$ & $-2.1640 \times 10^{6}$ & $1.2586 \times 10^{6}$ \\
\hline
\end{tabular}

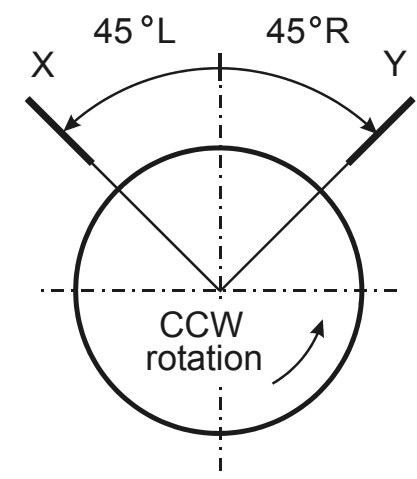

Fig. 3. Orientation of the proximity probes.

Figures 4 and 5 show the Bode plot of the $1 \mathrm{X}$ transient vibrations of the HP-IP turbine shaft measured at bearings $\# 1$ and \#2 during a reference machine runup. In Fig. 6 the amplitude of the $1 X$ transient vibrations of the LP turbine shaft measured at bearings \#3 and \#4 during the same runup is plotted against the machine rotational speed. Both amplitude and phase curves of the 1X vibrations illustrated in Figs 4 and 5 show that owing to the partial anisotropy 

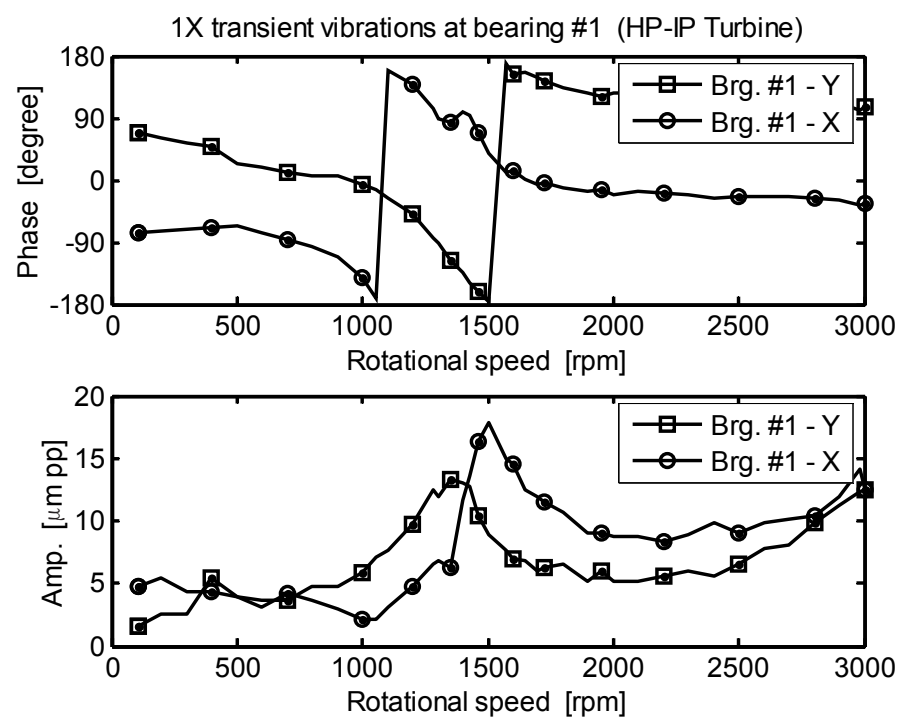

Fig. 4. Bode plot of the $1 \mathrm{X}$ transient vibrations measured at bearing $\# 1$ during a reference runup.
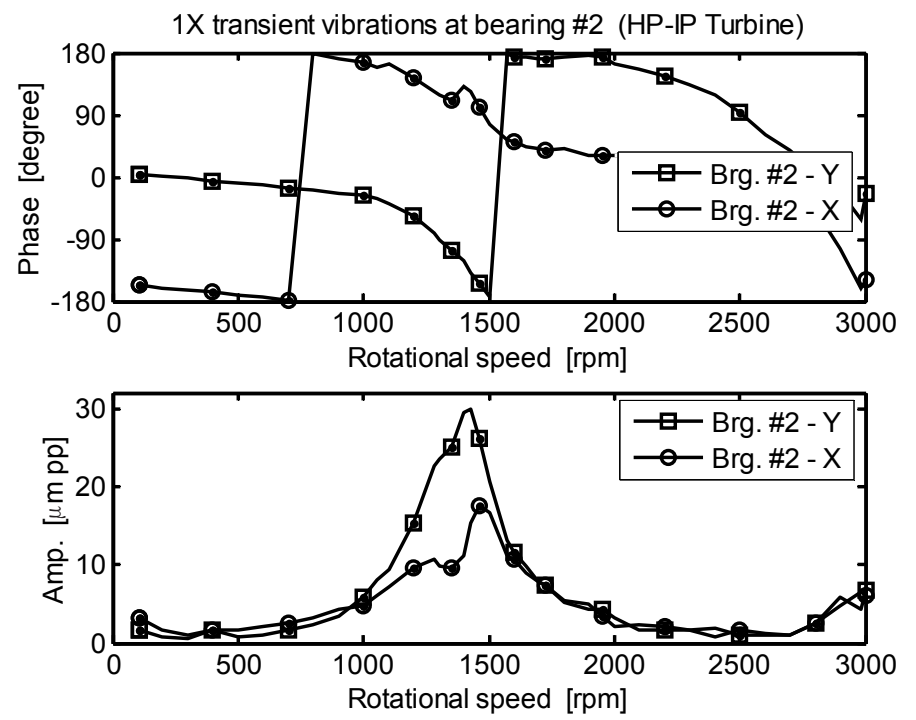

Fig. 5. Bode plot of the $1 \mathrm{X}$ transient vibrations measured at bearing \#2 during a reference runup.

of the oil-film journal bearings \#1 and \#2 this first resonance was split into two fairly spaced flexural critical speeds close to $1450 \mathrm{rpm}(24 \mathrm{~Hz})$. The low vibration levels occurred when approaching the operating speed, as well as when passing through the first balance resonance, indicate that the residual unbalance of the HP-IP turbine was rather small. Anyhow, in the rotational speed range, close to the first flexural critical speed, the amplification of the vibration levels was evident. Conversely, within the same speed range, the amplitude of the $1 \mathrm{X}$ vibrations of the LP turbine did not show significant changes. That is the dynamic behavior of the LP turbine showed to be scarcely influenced by the vibrations of the HP-IP turbine. Likely, although the shafts of the two turbines were connected by means of a common rigid coupling, the small flexural stiffness of the slim portion of the shaft-train between bearings \#2 and \#3, whose average diameter was not very large, significantly uncoupled the lateral vibrations of the two turbines. These characteristics of the experimental dynamic behavior of the unit were confirmed also by the results provided by a mathematical model developed by the authors to simulate and investigate the machine vibrations. 

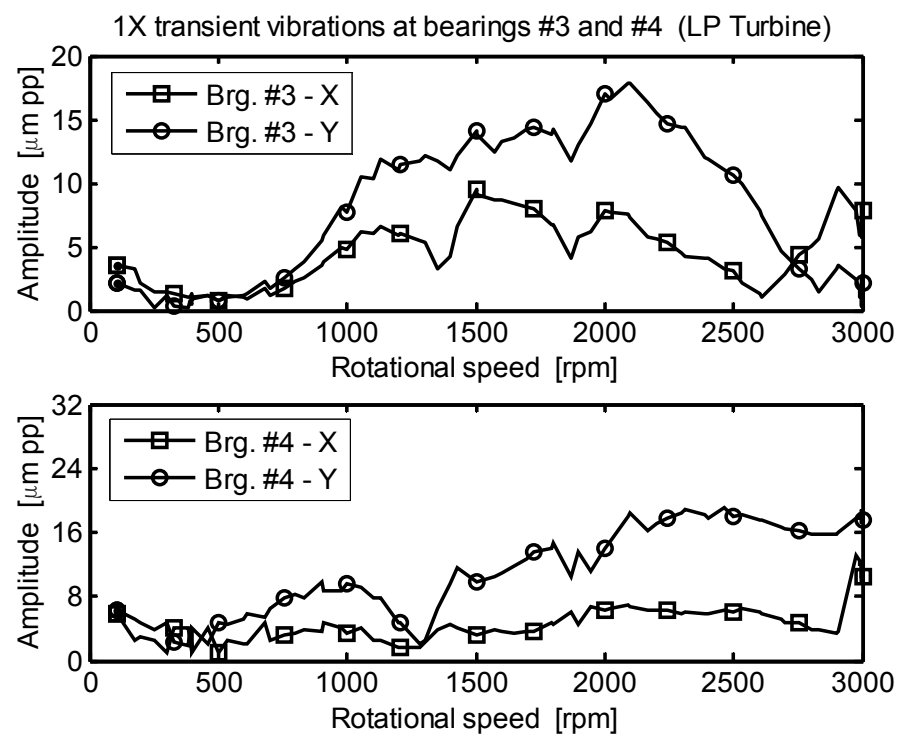

Fig. 6. Amplitude of the $1 \mathrm{X}$ vibrations of the LP turbine plotted against the rotational speed: data collected during the reference runup.
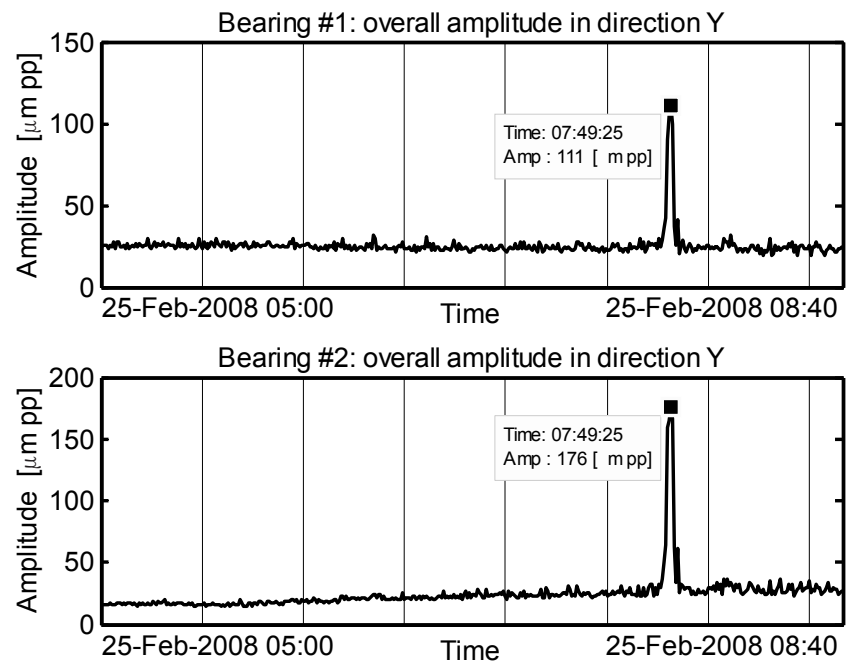

Fig. 7. Historic trend of the overall amplitude of the vibrations measured on the support \#2 (direction Y) at the end of a load rise at the operating speed of $3000 \mathrm{rpm}$.

In general, the vibrations of the HP-IP turbine measured in operating conditions were rather low. However, multiple events within which the level of these vibrations quickly raised and exceeded the machine trip limit (180 $\mu \mathrm{m}$ pp) were detected. These abnormal phenomena always occurred during the first megawatt load rise carried out after a machine runup performed with an initial cold thermal state of the unit. Therefore, it was supposed that the machine thermal transient could play a significant role in the occurrence of these abnormal vibrations.

Figure 7 shows the historic trend of the overall amplitude of the vibrations measured at the bearings \#1 and \#2, in the $\mathrm{Y}$ direction, at the end of the first load rise carried out after the machine reference runup: it is possible to note that the level of the HP-IP vibrations increased very quickly from about $25 \mu \mathrm{m}$ pp (peak-to-peak) to more than $100 \mu \mathrm{m}$ pp and reached $176 \mu \mathrm{m}$ pp at the most critical measurement point.

A timely small decrease of the megawatt load performed by the control room personnel caused a quick considerable decrease of the vibration level that shortly approached the original low values that preceded this abnormal event. 
Table 5

Maximum levels of the overall amplitude of the HP-IP and LP turbine vibrations occurred at the end of the load rise carried out during the observation interval

\begin{tabular}{lcc}
\hline & \multicolumn{2}{c}{ Direction } \\
\cline { 2 - 3 } & $\mathrm{X}$ & $\mathrm{Y}$ \\
\hline Bearing N. & {$[\mu \mathrm{m} \mathrm{pp}]$} & {$[\mu \mathrm{m} \mathrm{pp}]$} \\
$\# 1$ & 112.0 & 111.0 \\
$\# 2$ & 109.1 & 176.0 \\
$\# 3$ & 36.8 & 27.9 \\
$\# 4$ & 20.5 & 58.1 \\
\hline
\end{tabular}
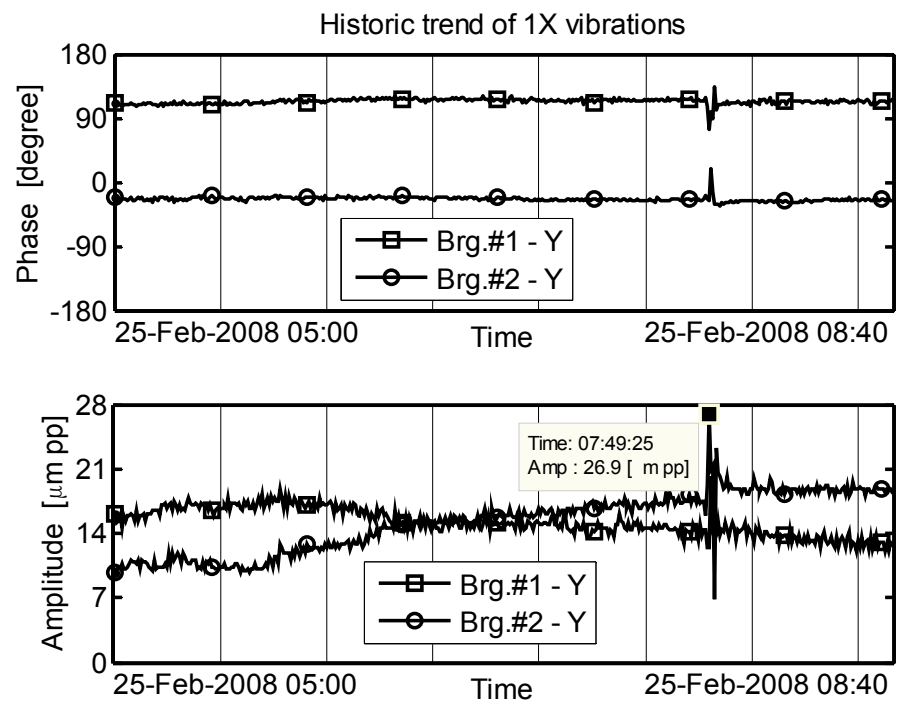

Fig. 8. Historic trend of the $1 \mathrm{X}$ vibrations measured on the support \#2 (direction $\mathrm{Y}$ ) at the end of a load rise.

Table 5 shows the values of the maximum peak of the overall amplitude of the HP-IP and LP turbine vibrations occurred at the end of the load rise carried out during the observation interval considered in Fig. 7. It is possible to note that this event of abnormal vibrations mainly affected the dynamic behavior of the HP-IP turbine.

Figure 8 shows the historic trend of both amplitude and phase of the synchronous vibrations (1X) measured at the bearings \#1 and \#2, in the Y direction, during the same observation interval of the monitoring data illustrated in Fig. 7.

The very low level of the $1 \mathrm{X}$ vibrations confirms that the residual unbalance of the HP-IP turbine was rather small, while the sharp and considerable peak of the overall amplitude of the shaft vibrations occurred when approaching the rated load (Fig. 7) caused only negligible effects on the $1 \mathrm{X}$ vibration.

In order to obtain more significant diagnostic information, the harmonic content of the HP-IP turbine vibrations measured during the occurrence of the abnormal dynamic behavior documented in Fig. 7 was evaluated. The frequency spectrum illustrated in Fig. 9 shows that the main contribution to the high peak of the overall amplitude of the vibrations measured on bearing \#2 was caused by the presence of a sub-harmonic component whose frequency was close to $23.25 \mathrm{~Hz}(1395 \mathrm{rpm})$. Therefore, the harmonic order of this vibration was $0.465 \mathrm{X}$.

Although this order was rather close to $0.5 \mathrm{X}$ the supposition that this abnormal behavior was caused by an oil-whirl instability onset was discarded since the turbine shaft was mounted on tilting-pad journal bearings that, in general, are scarcely influenced by unstable phenomena except occasional events of pad-fluttering [27,28].

Moreover, the noticeable sensitivity of the shaft vibrations to the megawatt load, observed during several monitoring periods, could be considered a clear symptom of the influence of the steam flow characteristics on the dynamic behavior of the HP-IP turbine. 


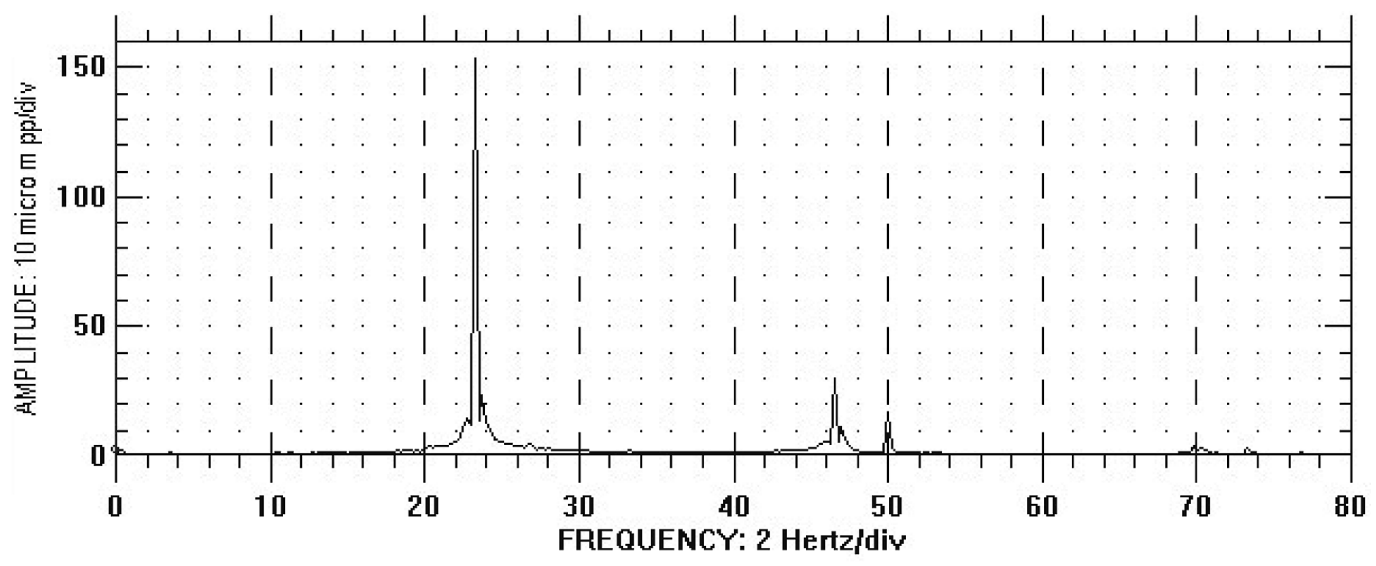

Fig. 9. Frequency spectrum of the vibrations measured on the support \#2 (direction Y) during the occurrence of abnormal vibration levels.

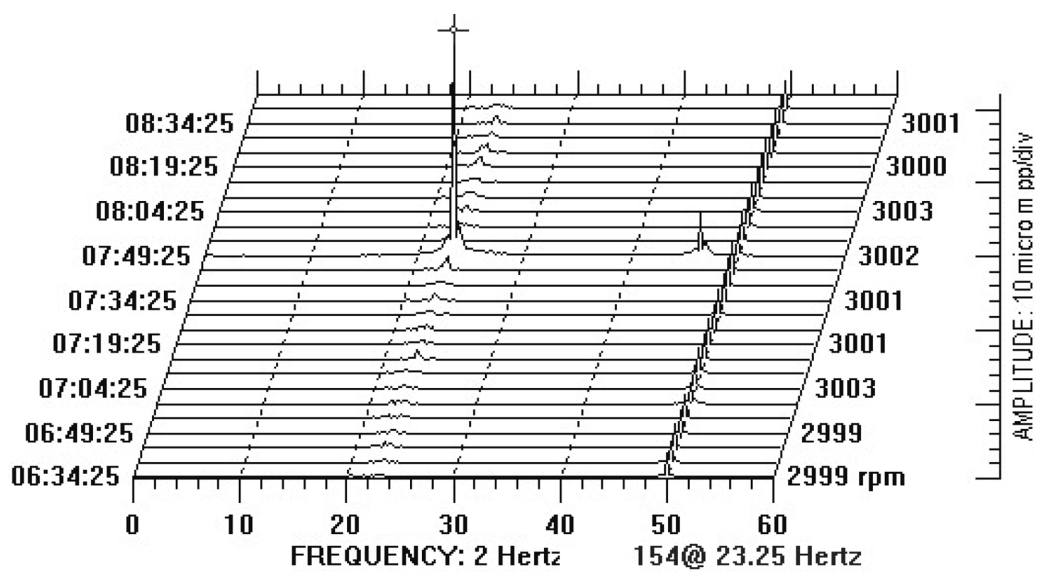

Fig. 10. Waterfall plot of the vibrations measured on the support \#2 (direction Y) during the occurrence of abnormal vibration levels.

The waterfall plot in Fig. 10 shows the sequence of spectra of the vibrations measured on bearing \#2 just before and after this event of abnormal subsynchronous vibrations. Owing to nonlinear effects, also a vibration harmonic component at $46.5 \mathrm{~Hz}$ is present.

In order to perform a more accurate investigation on the causes of the abnormal vibrations that occasionally affected the machine dynamic behavior in operating conditions, the average position of the journal inside bearings \#1 and \#2 was analyzed. Figure 11 shows the experimental centerline curves of the journal inside the above mentioned bearings of the HP-IP turbine measured during the reference runup. In the same figure the average journal position detected when approaching the rated power at the end of the first load rise is shown.

Accordingly to the oil-film journal bearing characteristics, the horizontal component of the centerline curves was negligible while the maximum vertical displacement of the journal, evaluated with respect to the central lower shoe, were consistent in comparison to the respective radial clearance and pre-load factor. During the first load rise and the consequent machine heating, the average position of the two journals showed some changes mainly caused by additional upward vertical displacements.

It is well known that pad-fluttering phenomena may occur when single shoes of tilting-pad journal bearings are lightly loaded. Owing to this, in horizontal shafts, the upper pads are more likely exposed to the risk that pad-fluttering phenomena occur. Therefore, taking into account that in the present case study the pre-load factor of the pads was not null, the average position of the journals inside the bearings of the HP-IP turbine measured when approaching the rated load seemed to be able to ensure a proper load on each pad. 


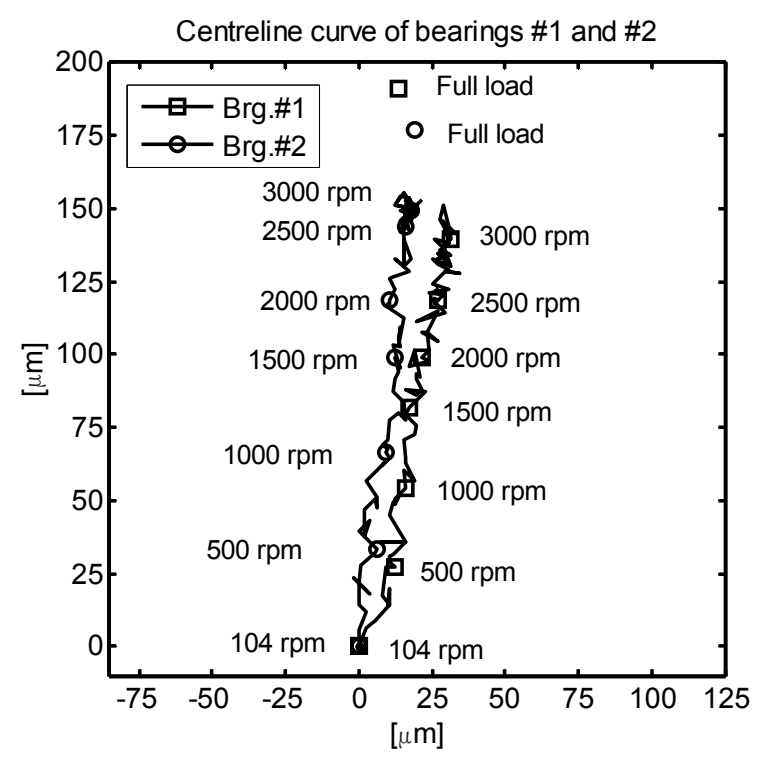

Fig. 11. Experimental centreline curves of the journal within bearings \#1 and \#2.
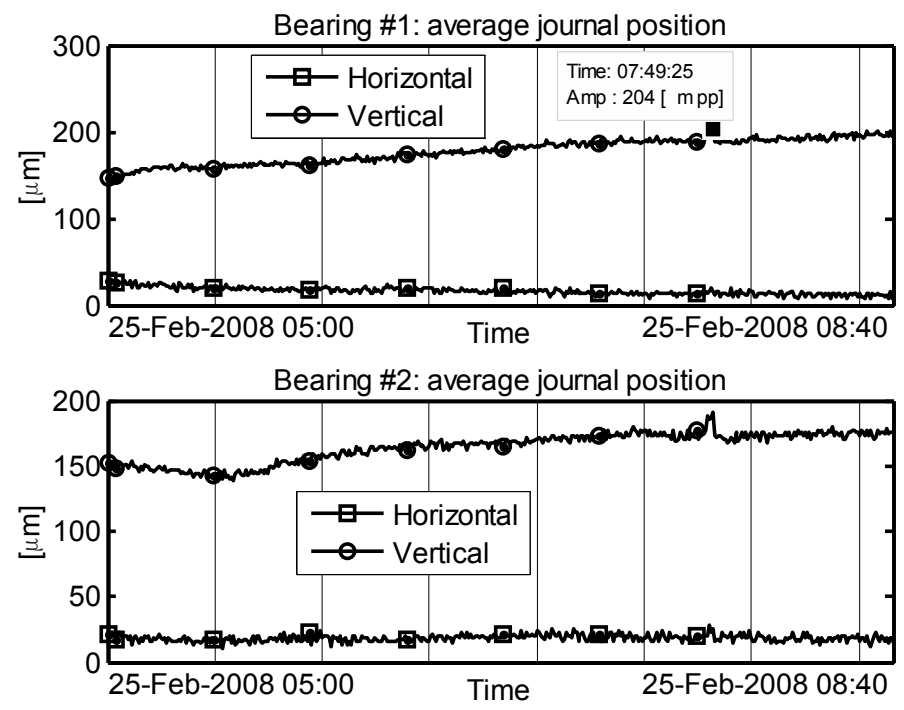

Fig. 12. Historic trend of the horizontal and vertical components of the average position of the journal inside bearings \#1 and \#2 measured in operating condition during a load rise.

Figure 12 shows the historic trend of the horizontal and vertical components of the average position of the journals inside bearings \#1 and \#2 measured in operating condition during the same observation interval considered to investigate the machine vibrations illustrated in Figs 7 and 8. It is possible to note that, in occasion of the occurrence of the abnormal dynamic behavior of the unit, the timely partial decrease of the megawatt load that caused the immediate significant decrease of the vibration levels caused only negligible changes of the average position of the journals inside the two bearings of the HP-IP turbine. However, the overall amplitude of the shaft vibrations quickly decreased and the unstable sub-synchronous harmonic component disappeared. These experimental findings indicate that the occurrence of the unstable vibrations that occasionally affected the dynamic behavior of the HP-IP turbine did not depend on the average position of the journals inside bearings \#1 and \#2. Therefore, the sudden and considerable changes of the level and harmonic content of the turbine vibrations were not caused by significant changes of bearing 


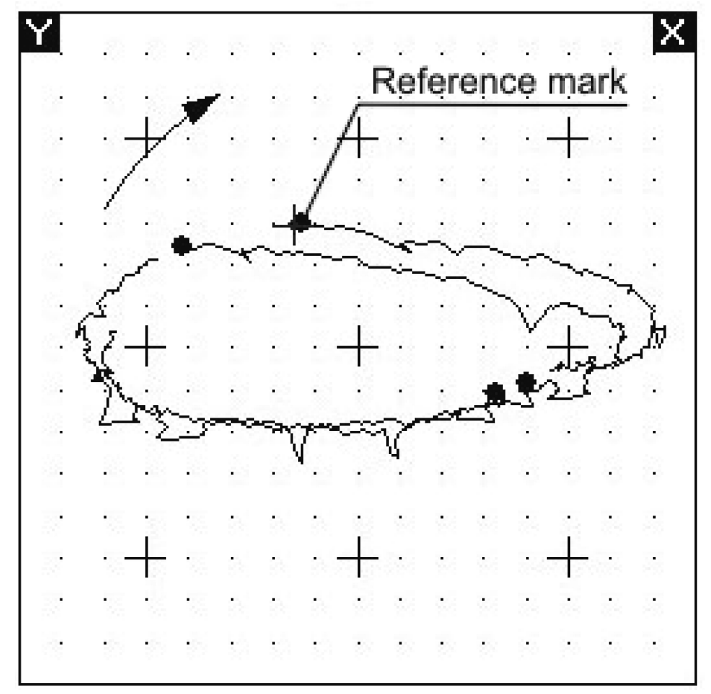

Fig. 13. Journal orbits measured on bearing \#1 during an event of abnormal vibrations of the HP-IP turbine.

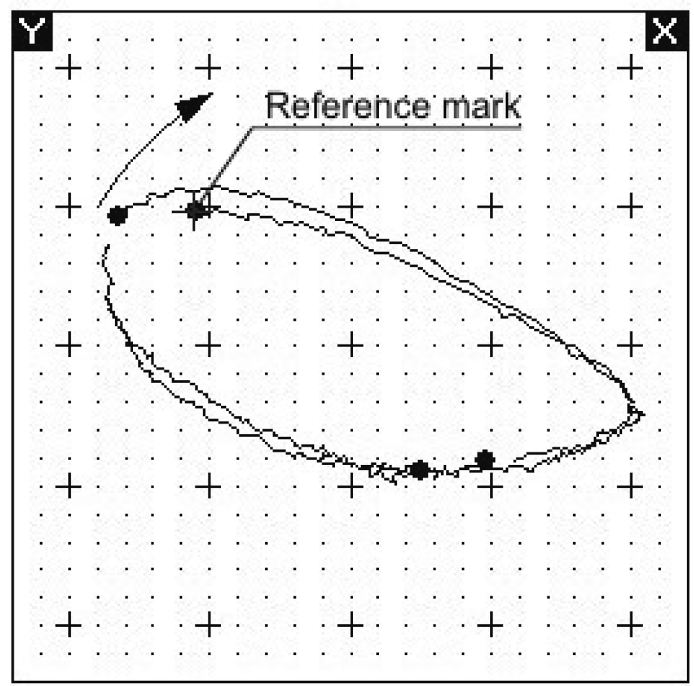

Fig. 14. Journal orbits measured on bearing \#2 during an event of abnormal vibrations of the HP-IP turbine.

loads, oil-film geometry and dynamic stiffness coefficients as commonly occurs during pad-fluttering phenomena.

Figures 13 and 14 show the journal orbits measured on bearings \#1 and \#2 during the occurrence of high levels of the subsynchronous vibrations. Although nearly two orbits are shown in each of these figures, four reference marks are detectable on each orbit curve: this means that four complete rotations of the shaft were necessary to allow the journal to draw nearly two orbits. This is in accordance with the presence of a sub-harmonic component that gave a predominant contribution to the overall amplitude of the turbine vibration. Figure 15 shows the short time history waveform of the vibration signals measured by the XY proximity probes that generated the orbits illustrated in Fig. 14: the effects of the unstable vibrations at nearly $23.2 \mathrm{~Hz}$ are evident.

Multiple events of high subsynchronous vibrations of the HP-IP turbine occurred at the end of the first load rise carried out after machine start-ups. In accordance with the significant repeatability of the symptoms of this malfunction, the order of the subsynchronous vibration was very close to $0.465 \mathrm{X}$. On the basis of these findings it was suspected that the abnormal dynamic behavior of the HP-IP turbine was caused by the occurrence of steam-whip 


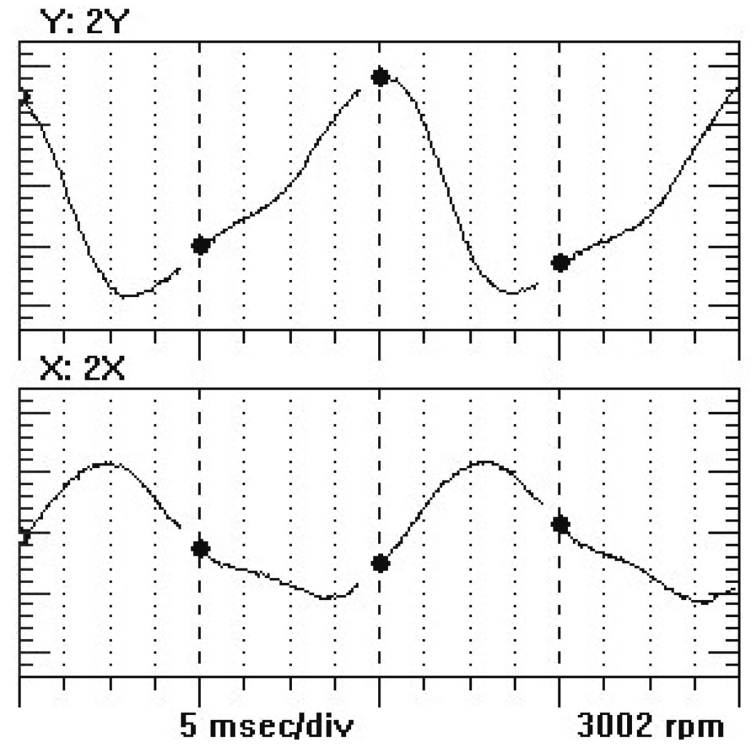

Fig. 15. Vibration signals measured on the support \#2 (XY probes) during an event of abnormal subsynchronous vibration levels of the HP-IP turbine.

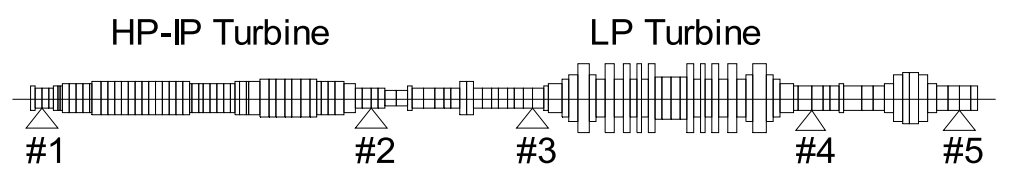

Fig. 16. Finite Element Model of the shaft-train composed of the HP-IP and the LP steam turbines.

instability onsets. In fact, the frequency that corresponded to the subsynchronous vibration was very close to the first flexural critical speed of the HP-IP turbine. This is one of the basic conditions for the occurrence of steam-whip instability phenomena.

With regard to the waterfall plot illustrated in Fig. 10, it is possible to note that low subsynchronous vibrations were already present in the frequency spectrum also before the occurrence of the quick increase of their amplitude caused by the progressive raise of the megawatt load. These findings confirm that destabilizing forces generated in some seals of the HP turbine caused the conditions for an incipient steam-whirl instability onset. When the load approached the rated value, the machine dynamic behavior became unstable. Owing to the considerable non-linear effects involved by this phenomenon the high subsynchronous vibrations at $23.25 \mathrm{~Hz}$ also caused a further harmonic component at $46.5 \mathrm{~Hz}$ (see Figs 9 and 10).

\section{Model-based investigation}

The dynamic behavior of the unit was investigated by means of a simulation model. This allowed studying the sensitivity of the machine vibrations to hardening phenomena that during load rises can affect the stiffness coefficients of the seals mounted on the steam turbines as well as to evaluate the stability margin of the unit. Figure 16 shows the FEM of a portion of the shaft-train composed of the HP-IP and the LP steam turbines. In the machine model also linearized stiffness and damping coefficients of the oil-film journal bearings, which depended on the shaft rotating speed, were considered. In contrast, in this preliminary analysis the stiffness coefficients of the seals of the turbines were discarded since their effects during coastdowns and runups is null or negligible.

In Table 6 the first six flexural critical speeds and the corresponding instability factors provided by an eigenvalue analysis are shown. The machine model was characterized by two critical speeds included in the range from $1400 \mathrm{rpm}$ to $1500 \mathrm{rpm}$. The corresponding instability factors were sufficiently far from the critical unit value. 
Table 6

Flexural critical speeds and instability factors associated with the first six eigenvalues of the model of the power unit

\begin{tabular}{lcc}
\hline $\begin{array}{l}\text { Critical speed } \\
{[\mathrm{rpm}]}\end{array}$ & Dimensionless damping factor & Instability factor \\
\hline 1165.8 & 0.07952 & 0.60579 \\
1437.1 & 0.07520 & 0.62261 \\
1497.3 & 0.03308 & 0.81225 \\
2172.3 & 0.04996 & 0.73029 \\
2327.8 & 0.23633 & 0.21693 \\
3876.2 & 0.42146 & 0.05393 \\
\hline
\end{tabular}
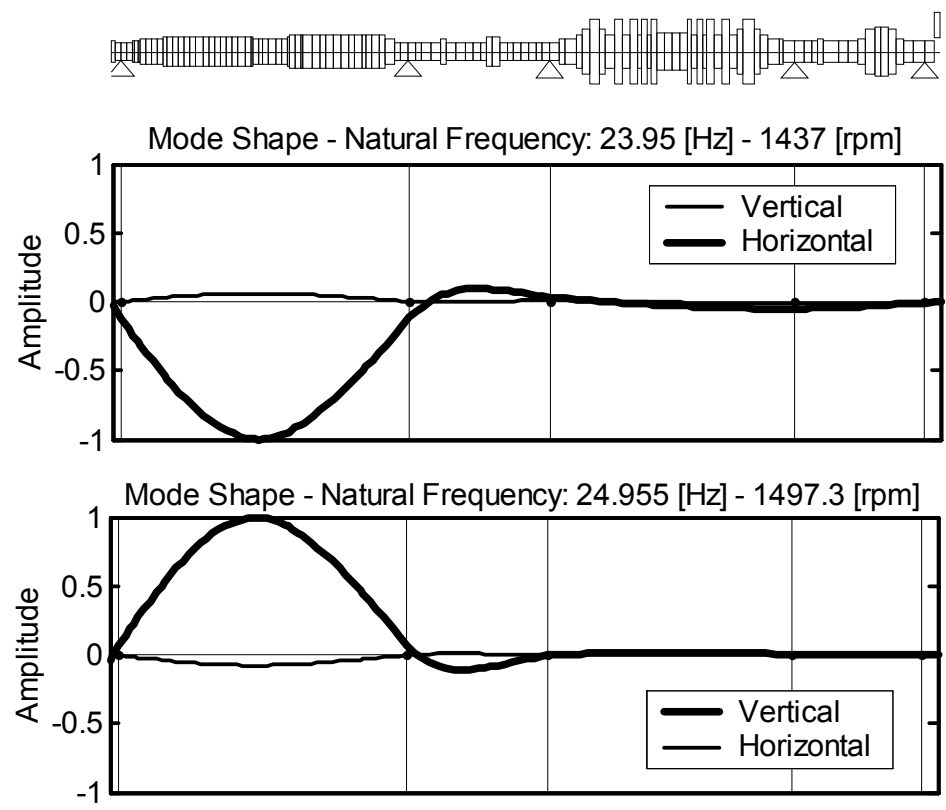

Fig. 17. Normal modes associated with the 2nd and 3rd eigenvalues of the model that correspond to the 1st balance resonance of the HP-IP steam turbine.

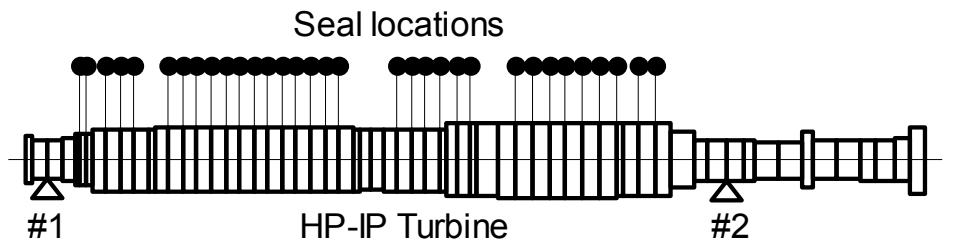

Fig. 18. Finite Element Model of the HP-IP turbine and location of the main groups of seals.

Figure 17 shows the two normal modes of the shaft-train associated with the second and third eigenvalues of the machine model. Both eigenvalues are correlated with the first bending mode of the HP-IP turbine, that is with the first flexural critical speed of this turbine shaft. This result is in good accordance with the experimental evidences pointed out by the $1 \mathrm{X}$ transient vibrations illustrated in Fig. 5. Moreover, it is well known that when steam-whip phenomena occur they often excite the first " $U$ " bending normal mode of the shaft that, in consequence, is affected by unstable subsynchronous vibrations.

In a further model of the unit, the stiffness coefficients of the seals of the steam turbines were taken into account. Figure 18 shows the portion of the FEM of the shaft-train in which the HP-IP turbine is described. In this figure the location of the main seals mounted along this shaft is shown. 


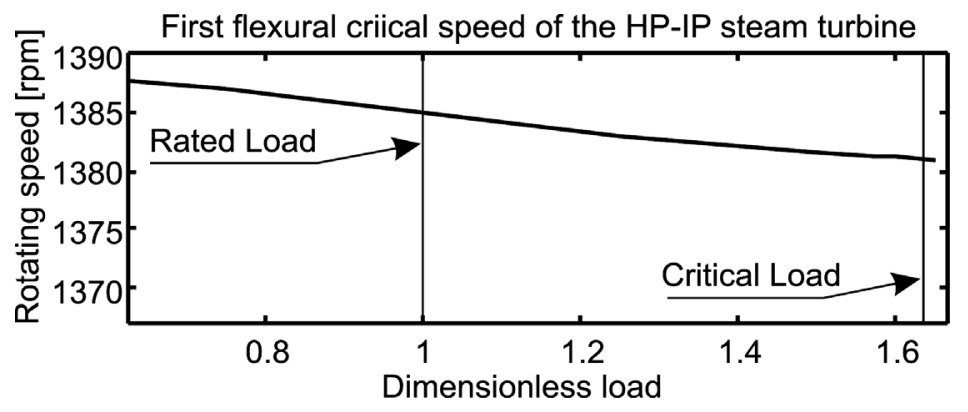

Fig. 19. First flexural critical speed of the HP-IP turbine plotted vs. the dimensionless load.

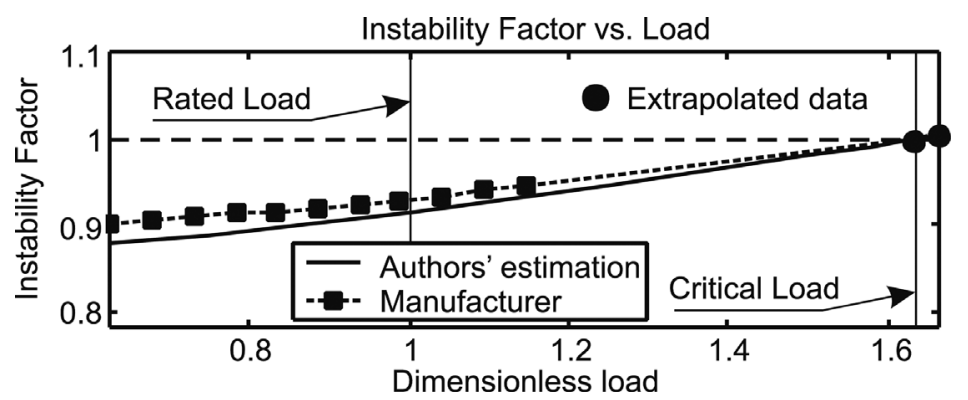

Fig. 20. Instability Factor associated with the eigenvalue n.3 plotted vs. the dimensionless load.

A sensitivity analysis was performed by evaluating the model eigenvalues and the respective instability factors considering the seal stiffness coefficients associated with increasing values of the megawatt load. The nominal values of the stiffness coefficients of the seals provided by the turbine manufacturer, evaluated at the rated load, were taken into account. Since the number of seals mounted along the HP-IP turbine was rather large, equivalent stiffness coefficients were determined in order to model groups of seals.

In accordance with the diagnostic strategy above described, the cross-coupled stiffness coefficients associated with a generic value $L_{j}$ of the load were estimated by means of the Eq. (8). Within each analysis, these stiffness coefficients were included in the machine model, evaluated for different loads.

Then, the system eigenvalues were evaluated considering the operating speed of the shaft-train. The stability margin of the unit was determined by considering also load values higher than the rated load of the unit (240 MW).

The effects of the seal stiffening, caused by the load increase, on the eigenvalue n.3 (see Table 6), associated with the first bending mode of the HP-IP turbine were analyzed in detail. In Fig. 19 the flexural critical speed associated with the eigenvalue $n .3$ is plotted vs. the dimensionless value of the megawatt load, that is the ratio between the load $L_{j}$ and the rated load $L_{r}$. The seal stiffening caused a partial decrease of the value of the first critical speed of the HP-IP turbine.

In Fig. 20 the instability factor associated with the eigenvalue n. 3 is plotted vs. the dimensionless value of the megawatt load. It is possible to note that the seal stiffening caused a progressive increase of the instability factor that reached the critical unit value for a dimensionless load equal to 1.64 (394 MW). This is a mathematical condition for the occurrence of unstable vibrations of the shaft-train. That is destabilizing forces generated at the operating speed within some groups of seals mounted on the HP turbine can excite the first flexural critical speed of the shaft.

If the real part of the corresponding eigenvalue becomes positive, these subsynchronous vibrations are unstable and their amplitude can increase very quickly.

Table 7 shows the first six flexural critical speeds and the corresponding instability factors provided by the eigenvalue analysis performed considering a dimensionless megawatt load equal to 1.65.

Figure 21 shows the $1 \mathrm{X}$ filtered orbits of the journals measured at bearings \#1 and \#2, in normal on-load operating conditions, only few minutes before the occurrence of the instability onset documented in the waterfall plot illustrated in Fig. 10. The reference marks of the two $1 \mathrm{X}$ filtered orbits shown in Fig. 21 are out-of-phase. 
Table 7

Flexural critical speeds and instability factors associated with the first six eigenvalues of the model of the power unit evaluated considering a dimensionless megawatt load equal to 1.65

\begin{tabular}{lcc}
\hline $\begin{array}{l}\text { Critical speed } \\
\text { [rpm] }\end{array}$ & Dimensionless damping factor & Instability factor \\
\hline 1218.6 & 0.02404 & 0.85977 \\
1334.4 & 0.09051 & 0.56493 \\
1380.9 & -0.00091 & 1.00571 \\
1952.2 & 0.05627 & 0.70181 \\
2462.7 & 0.09912 & 0.53480 \\
3693.5 & 0.14625 & 0.39498 \\
\hline
\end{tabular}

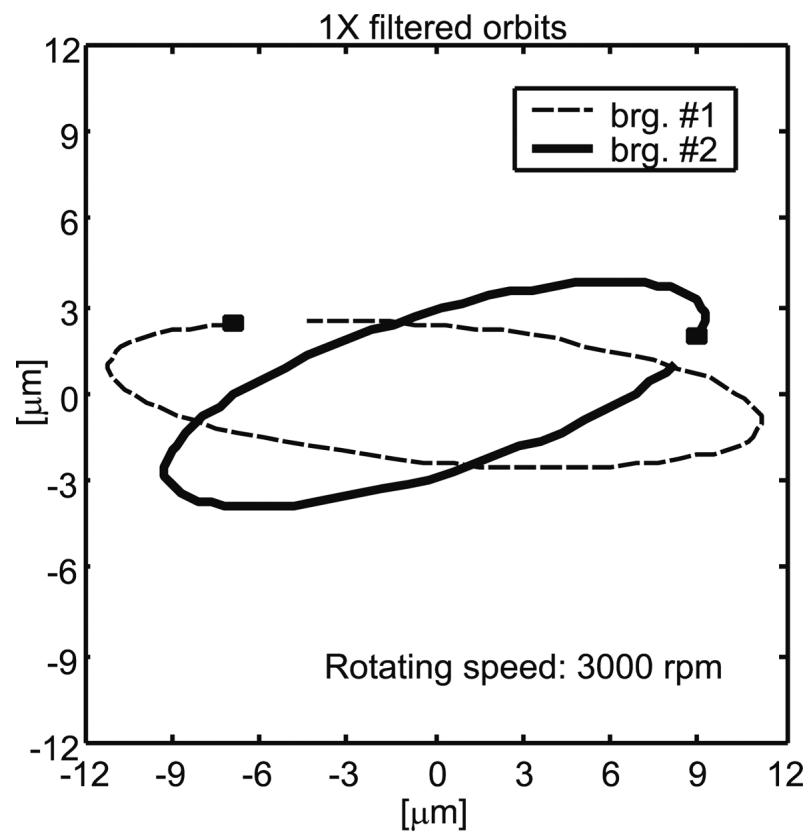

Fig. 21. $1 \mathrm{X}$ filtered journal orbits measured at bearings \#1 and \#2 few minutes before an instability onset.

However, when the steam-whip instability onsets occurred, they significantly excited the first flexural normal mode of the HP-IP turbine associated with a natural frequency close to $23 \mathrm{~Hz}$. Figures 13 and 14 show the unfiltered journal orbits measured at bearings \#1 and \#2 in occasion of the instability onset documented in Figure 10. Since the subsynchronous harmonic component at the frequency equal to $23.2 \mathrm{~Hz}$, very close to the first balance resonance, gave the main contribution to the overall amplitude of the shaft vibration the reference marks, plotted on these journal orbits, associated with the same initial instant were nearly in-phase. Therefore, although the machine rotating speed was $3000 \mathrm{rpm}$, the dynamic behaviour of the HP-IP turbine was in accordance with the shape of the shaft normal mode associated with the theoretical first balance resonance $(1437 \mathrm{rpm})$ that was excited by the destabilising forces generated in the seals.

These findings about the journal orbits, which could seem obvious, are an important confirmation of the physical phenomena that are caused on real machines by the occurrence of steam-whip instability onsets.

A protection system that causes a sudden machine trip as well as a timely decrease of the megawatt load, and then of the stiffness coefficients of the seals, can avoid the occurrence of catastrophic failures.

In Fig. 20 the instability factor curve evaluated by the authors is compared to the respective curve that the turbine manufacturer provided only in the range below a dimensionless load equal to 1.14. However, on the basis of the available data it was possible to extrapolate a reliable estimate of the instability factor associated with the critical dimensionless load of 1.64 identified by the authors. The result of this investigation is a prediction of the instability 
Table 8

Flexural critical speeds and instability factors associated with the first six eigenvalues of the model of the power unit after flexural stiffness changes of the HP-IP turbine

\begin{tabular}{lcc}
\hline $\begin{array}{l}\text { Critical speed } \\
{[\mathrm{rpm}]}\end{array}$ & Dimensionless damping factor & Instability factor \\
\hline 1142.2 & 0.10110 & 0.52809 \\
1463.8 & 0.10216 & 0.52452 \\
1557.8 & 0.03134 & 0.82119 \\
2101.0 & 0.05595 & 0.70321 \\
2450.8 & 0.14093 & 0.40885 \\
3751.3 & 0.15405 & 0.37546 \\
\hline
\end{tabular}

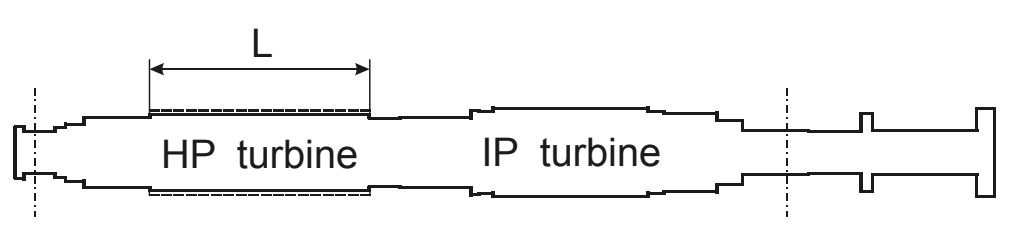

Fig. 22. Sketch of stiffness change on HP turbine.

factor that the model of the turbine manufacturer would have given if the analysis was performed over a larger load range. This extrapolated value of the instability factor is very close to unity. Therefore, the results of the sensitivity analysis performed by the authors are in good accordance with those obtained by the turbine manufacturer.

The stability margin obtained by means of both investigations is close to 0.64 : larger safety margins, e.g. higher than 1.5 , and would have been necessary to reduce the risk of steam-whip instability onsets, machine outages and serious damage.

In the present case study it is possible to suppose that the significant thermal transient that affected the unit during the first load rise carried out at the end of a machine start-up caused a temporary critical alignment condition of the shaft-train with respect to the turbine casing. Likely, owing to this the clearance of some groups of seals of the HP turbine could reach abnormal values causing an excessive unexpected hardening of the cross-coupled stiffness coefficients of the seals. Therefore, in this abnormal operating condition, even at megawatt loads close to the rated load $(240 \mathrm{MW})$, it could be possible to generate the critical situation that with an ideal rotor-to-seal alignment would occur with a virtual load close to $400 \mathrm{MW}$ as indicated by the model predictions.

With regard to the capability of the seal stiffening to generate a system eigenvalue characterized by a positive real part, which can cause unstable vibrations, excessively low values of the flexural stiffness of the turbine shaft can cause detrimental effects. Often the rotor of the HP turbines are rather slim. Therefore, the increase of the flexural stiffness, caused by even a small increase of the average diameter of the shaft, can be sufficient to significantly reduce the sensitivity of the turbine dynamic behavior to steam-whip instability phenomena. In accordance with this assumption the experimental value of the first balance resonance of the HP-IP turbine analyzed in the present case study was rather low (nearly $1480 \mathrm{rpm}$ ).

A further investigation was performed to study the sensitivity of the risk of the occurrence of steam-whip instability phenomena to changes of the flexural stiffness of the HP-IP turbine. Obviously fluid-dynamic restrictions limit the extent of the increase in the average diameter of the shaft. Therefore, in the present case study the diameter of the main body of the HP turbine, where fourteen bladed disks and a large number of seals are mounted, was increased of only 15 per cent (Fig. 22).

This modified HP turbine shaft was considered into a new simulation model. The first six flexural critical speeds of the modified shaft-train are reported in Table 8: these results can be compared to those shown in Table 6. Obviously, the partial increase of the diameter of the main body of the HP turbine causes a small increase of the second and third critical speeds of the shaft-train that are associated with the first "U" bending mode of the HP-IP turbine.

Then, the eigenvalues and eigenmodes of the machine model were evaluated considering a shaft rotational speed equal to the operating speed and increasing values of the dimensionless load. In Fig. 23 the third flexural critical speed of the shaft-train is plotted against the dimensionless load. In the same figure, these results are compared to 


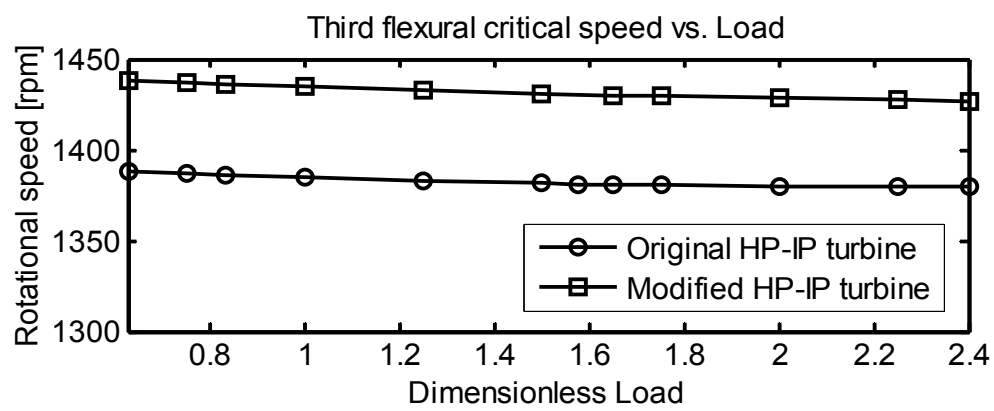

Fig. 23. Third flexural critical speed plotted vs. the dimensior less load, after flexural stiffness cbanges of the HP-IP truhine.

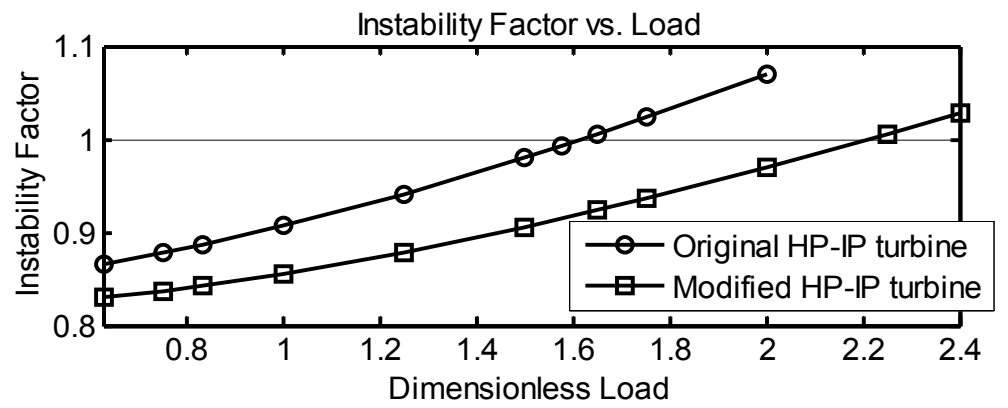

Fig. 24. Instability factor associated with the elgenvalne vs. the dimensionless load, after flexural stiffness changes of the HP-IP trubine.

those obtained in the same conditions by means of the original model of the shaft-train. The small increase of the diameter of the HP turbine caused an increase of about $3.6 \%$ of the third flexural critical speed.

In the end, the stability margin of the modified shaft-train was investigated. In Fig. 24 the instability factor associated with the eigenvalue $n .3$ is plotted against the dimensionless load. In the same figure these results are compared to those obtained by means of the original model of the shaft-train. It is possible to note that instability factor exceeded the unity limit for a dimensionless load close to 2.24. Therefore, the small increase of the HP turbine diameter caused a significant increase of the stability margin from 0.65 to 1.24 . This result was not influenced by significant changes of the shape of the normal modes of the shaft-trains associated with the third eigenvalue of the two models. In fact, the Modal Assurance Criterion (MAC) evaluated considering the eigenmodes associated with the eigenvalue $n .3$ of the two models and the dimensionless loads that caused the instability factor to reach the critical unity value was 0.9999 .

This means that in case of slim shafts an important increase of the stability margin can be obtained by means of even small changes of suitable portions of the HP turbine.

These results are in accordance with the high sensitivity of slim shafts to the effects caused by the hardening of the cross-coupled stiffness coefficients of the seals: that is to the occurrence of the condition for the generation of unstable vibrations.

\section{Conclusions}

In addition to the geometric properties of the seals, the characteristics of the steam flow gives a basic contribution to the occurrence of steam-whip instability phenomena in power units. Model-based techniques can be used to simulate the machine dynamic behavior as well as to estimate the stability margin of the rotor system.

The hardening of the cross-coupled stiffness coefficients of the seals caused by a rise of the steam pressure and flow can cause important changes in the eigenvalues and eigenmodes of the mathematical model of the rotating machine. A parametric analysis can be performed to determine the threshold level of the steam flow that causes the 
real part of the eigenvalue associated with the first flexural normal mode of the turbine shaft to become positive. This causes the conditions for the occurrence of unstable vibrations.

Seal misalignments, e.g. induced by the thermal transients that can affect power units during load rises, can cause unexpected and undesired values of the seal stiffness coefficients, which can reach higher levels in comparison to the corresponding reference values obtained considering an ideal rotor-to-seal alignment.

The sensitivity of the stability margin of the machine-train on seal misalignments can be studied with model-based techniques. This strategy allows the changes in the eigenvalues and eigenmodes of the rotor system due to changes in the seal stiffness coefficients to be investigated.

In this paper the results of the analysis of the stability margin of a large power unit that was affected by unstable vibrations in on-load operating conditions caused by steam-whirl instability phenomena have been shown and discussed. The effects on the eigenvalues and eigenmodes of the machine model caused by seal misalignments and raises of the steam flow have been simulated. The results of these investigations are in good accordance with the value of the stability margin obtained on the basis of the experimental findings.

\section{References}

[1] T. Yamamoto and Y. Ishida, Linear and Nonlinear Rotordynamics, John Wiley and Sons, Inc., New York, pp. $210-214$.

[2] E. Capone, Oil whirl in journal bearings under no load conditions, Wear 26(2) (1973), 207-217.

[3] A. Muszynska, Whirl and Whip-Rotor/Bearing Stability Problems, Journal of Sound and Vibrations 110(3) (1986), 443-462.

[4] M.L. Adams, Keep rotor vibration under control, Power 122(8) (1978), 28-29.

[5] E. Krämer, Selbsterregte Schwingungen von Wellen infolge Querkraefte (Self-excited vibrations of shafts due to transverse forces), Brennst-Waerme-Kraft 20(7) (1968).

[6] Sz.J. Kubiak, D. Childs, M. Rodriguez and M.C. García, 2007, Investigation into a "Steam whirl" which affected HP rotors of 300 MW steam turbines, Proceedings of the ASME Power Conference 2007 (17-19 July 2007), 291-298.

[7] E. Pollman, H. Schwerdtfeger and H. Termuehlen, Flow excited vibrations in high pressure turbines (Steam whirl), ASME Journal of Engineering for Power 100(2) (1978), 219-228.

[8] H.J. Thomas, Instabile Eigenschwingungen von Turbinenlaeufern, angefacht durch die Spaltstroemungen in Stopfbuchsen und Beschaufelungen (Unstable vibrations of turbine rotors excited by clearance flows in sealings and bladings), Bull De l'AIM 71(11/12) (1958), 1039-1064.

[9] J. Alford, Protecting turbomachinery from self-excited rotor whirl, ASME Journal of Engineering for Power 87(4) (1965), 333-344.

[10] D.E. Bently and A. Muszynska, Role of Circumferential Flow in the Stability of Fluid-Handling Machine Rotors, Proceedings of The Fifth Workshop on Rotordynamic Instability Problems in High-Performance Turbomachinery, Texas, USA, NASA CP 3026, 1988, pp. 415-430.

[11] A. Muszynska, 1990, The Role of Flow-Related Tangential Forces in Rotor/Bearing/Seal System Stability in the Stability of Fluid-Handling Machine Rotors, Proceedings of the 3rd International Symposium on Transport Phenomena and Dynamics of Rotating Machinery, ISROMAC-3, Honolulu, Hawaii, USA.

[12] A. Muszynska, Transition to Fluid-Induced Limit Cycle Self-Excited Vibration of a Rotor and Instability Threshold 'Hysteresis', International Journal of Rotating Machinery 5(2) (1999), 123-133.

[13] D.M. Childs, Turbomachinery Rotordynamics - Phenomena, Modeling and Analysis, John Wiley and Sons, Inc., New York, 1993, pp. 227-354.

[14] H. Benckert and J. Wachter, Flow induced spring constants of labyrinth seals, IMechE paper C258/80, 1980, pp. 53-63.

[15] L. Hauck, Measurement and evaluation of swirl-type flow in labyrinth seals of conventional turbine stages, NASA Conference Publication, 1982, pp. 242-259.

[16] L. Hauck, Vergleich gebraeuchlicher Tubinenstufen hinsichtlich des Auftretens spaltstroemungsbedingter Kraefte (Comparison of usual turbine stages as regards clearance flow induced forces), Konstruktion 33(2) (1981), 59-64.

[17] J. Schettel and R. Nordmann, Rotordynamics of turbine labyrinth seals - a comparison of CFD models to experiments, IMechE paper C623/018, 2004, 13-22.

[18] N. Bachschmid, P. Pennacchi and A. Vania, Steam whirl stability margin in a power unit, Proceedings of ISMA - Int. Conf. on Noise and Vibration Engineering, Leuven, Belgium, ISBN 90-73802-83-0, 2006, pp. 3561-3575.

[19] N. Bachschmid, P. Pennacchi and A. Vania, Steam-whirl analysis in a high pressure cylinder of a turbo generator, Mechanical Systems and Signal Processing 22(1) (2008), 121-132.

[20] D.E. Bently and A. Muszynska, Frequency Swept Rotating Input Perturbation Techniques and Identification of Fluid Force Models in Rotor/Bearing/ Seal Systems and Fluid Handling Machines, Journal of Sound and Vibration 143(1) (1990), $103-124$.

[21] H. Kanki, H. Fujii, A. Hizume, T. Ichimura and T. Yamamoto, Solving Nonsynchronous Vibration Problems of Large Rotating Machineries by Exciting Test in Actual Operating Condition, Proceedings of IFToMM International Conference on Rotordynamics, Tokyo, Japan, 1986, pp. 221-225.

[22] M. Lalanne and G. Ferraris, 1998, Rotordynamics Prediction in Engineering, 2nd Edition, John Wiley and Sons Ltd., Baffins Lane, Chichester, West Sussex PO19 1UD, England, ISBN 0471926337.

[23] A. Vania, On the identification of foundation of a large turbogenerator unit by the analysis of transient vibrations, Proceedings of IMECHE 7th Int. Conf. on Vibrations in Rotating Machinery, Nottingham, UK, C576/076/2000, 2000, pp. 313-322. 
[24] P. Pennacchi, N. Bachschmid, A. Vania, G.A. Zanetta and L. Gregori, of modal representation for the supporting structure in model-based fault identification of large rotating machinery: part 1 - theoretical remarks, Mechanical Systems and Signal Processing 20(3) (2006), $662-681$.

[25] K.L. Cavalca, P.F. Cavalcante and E.P. Okabe, An investigation on the influence of the supporting structure on the dynamics of the rotor system, Mechanical Systems and Signal Processing 19(1) (2005), 157-174.

[26] A. Muszynska, 2005, Rotordynamics, Taylor and Francis Group, a CRC Press book, New York, USA, ISBN 0824723996.

[27] D.J. Hargreaves and M. Fillon, Analysis of a tilting pad journal bearing to avoid pad fluttering, Tribology International 40(4) (2007), 607-612.

[28] S.H. Yang, C. Kim and Y.-B. Lee, Experimental study on the characteristics of pad fluttering in a tilting pad journal bearing, Tribology International 39(7) (2006), 689-694. 

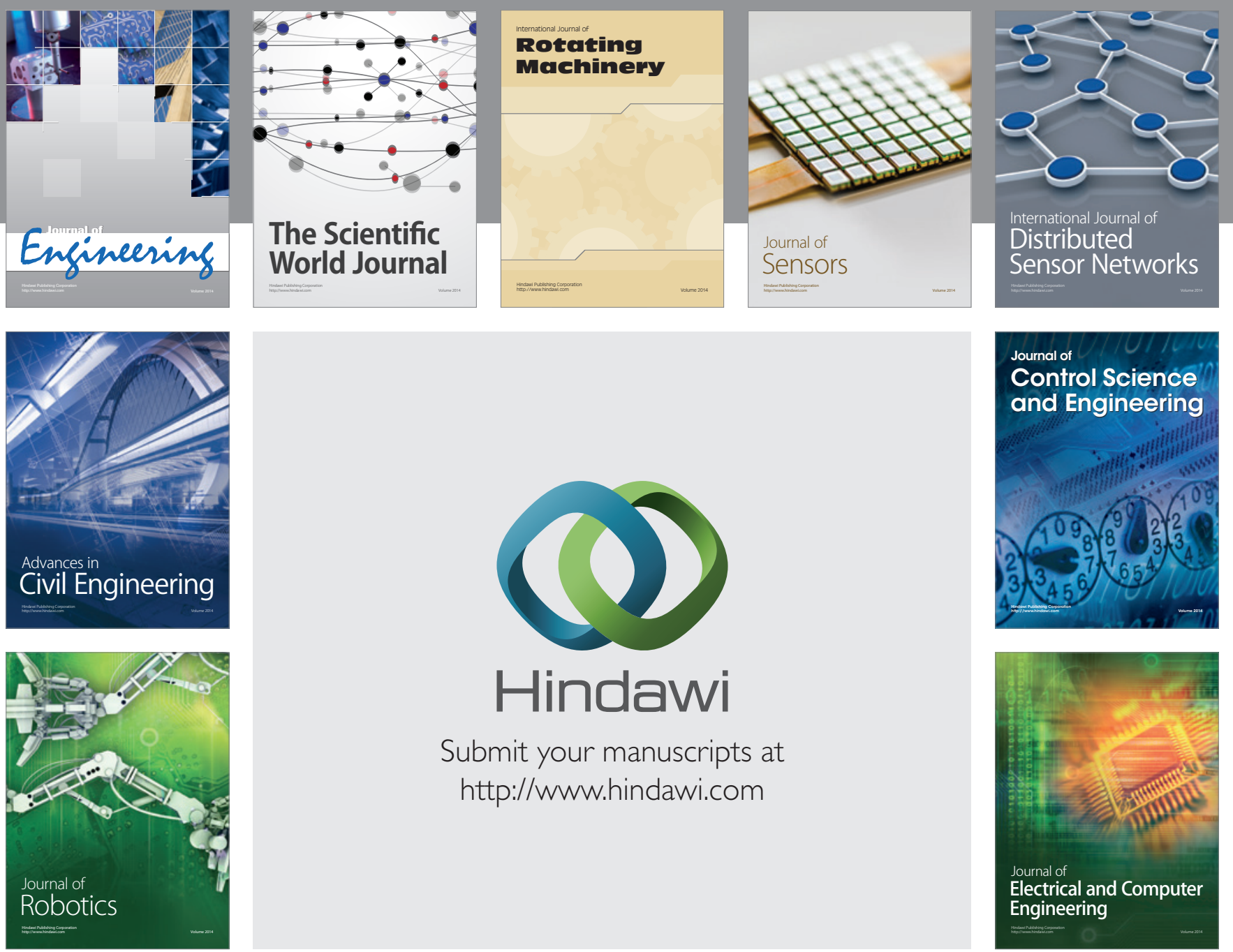

Submit your manuscripts at

http://www.hindawi.com
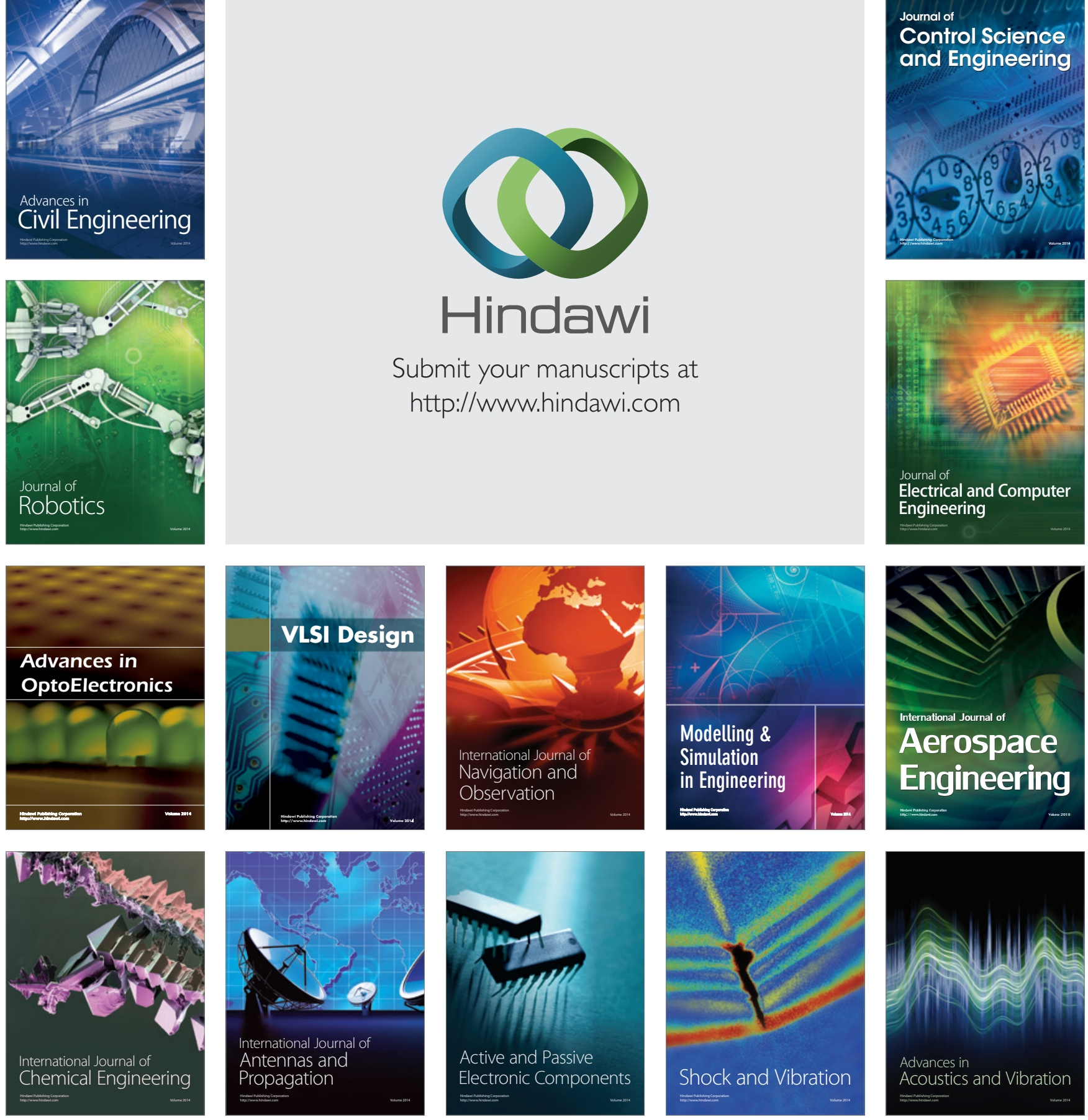